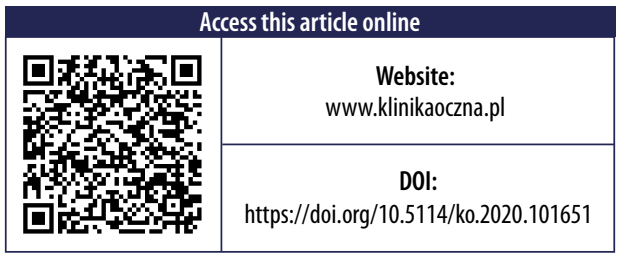

\title{
Tear film disorders as a manifestation of various diseases and conditions
}

\author{
Łucja Niezgoda ${ }^{1,2}$, Ewa Fudalej ${ }^{1,2}$, Anna Nowak ${ }^{1,2}$, Dorota Kopacz ${ }^{1,3}$ \\ 'Medical University of Warsaw, Warsaw, Poland \\ ${ }^{2}$ Student Research Club at the Department of Ophthalmology, Infant Jesus Teaching Hospital, Warsaw, Poland \\ ${ }^{3}$ Department of Ophthalmology, Infant Jesus Teaching Hospital, Warsaw, Poland
}

\begin{abstract}
The tear film consists of multiple layers, traditionally categorized as three separate units (the outermost lipid layer, the middle aqueous layer and the innermost mucins). Each building substance of the tear film has a specific role in its proper functioning and is prone to certain disturbances caused by both local and general disorders. A systematic review of the recent literature was conducted, with data obtained via PubMed. The authors focused on tear film disorders as a manifestation of various diseases and conditions,
\end{abstract}

with consideration of the current classification and diagnostic approaches. The elaborate composition of the ocular surface results in the diversity of problems affecting it. Bearing in mind the extensiveness of the subject, the most common and clinically important defects were selected. Defining the etiology of some disturbances can be very complex, but it is crucial for proper diagnosis and treatment.

KEY WORDS: ocular surface, tear film, tear dysfunction, tear film alterations.

\section{INTRODUCTION}

The external part of the eye is constantly exposed to the environment. Therefore, it is protected by the ocular surface (OS) - a unit consisting of the cornea, conjunctiva (bulbar, tarsal), lacrimal glands and lids (definition suggested by Thoft and Friend in 1979) [1]. The tear film fills the conjunctival sac and hydrates the OS [2].

The tear film consists of three main components. Traditionally, they are categorized as three separate units: the outermost oily layer, the middle aqueous layer and the innermost mucins $[2,3]$. More recent articles postulate a two-layer model (the lipid and the muco-aqueous phase) [4], while some authors go as far as stating that the tear film is a single unit that acts like a fluid shell [5].

The role of the tear film includes cleansing, lubrication and nourishment of the OS, creating a smooth, refractive surface for the light to pass freely and physical and immunological protection against infections [6-25] (Table I).

The tear film is a dynamic unit that washes over the eye surface and can be described by its four main characteristics, i.e. secretion, evaporation, drainage and absorption. Secreted elements - under control of the lacrimal unit - are distributed over the OS by the lids during blinking and hover in the lipid and aqueous phase in the interblink. There, because of the direct exposure to the environment, its evaporation occurs, carefully restrained by the lipids. In time, tears are drained by the canaliculi and puncta and absorbed mostly by the epithelial cells of the nasolacrimal duct $[26,27]$. Any disruption in this dynamic process can lead to tear film instability, which can be investigated by measuring the tear film breakup time (TBUT). This test is performed either after fluorescein instillation or with non-invasive methods [28], among which lateral shearing interferometry seems most promising [29]. The functions of the ocular surface, tear secretion and blinking rate are regulated by the nervous, endocrine, immune and circulatory systems [30], in order to assure even distribution of tears over the OS.

The prevalence of tear film disorders varies depending on population, sex, and age [31]. Many risk factors are being investigated: diabetes, dyslipidemia, autoimmunological diseases, ophthalmic surgery, the use of certain medications, air pollution, sleep quality, and allergies [32-37]. As of now, it is generally agreed that the population at highest risk are older women [38]. In Western China, a study reported a $27.8 \%$ dry eye disease incidence [39], while in Spain it is estimated as $18.4 \%$ [40] and in the USA as $6.8 \%$ [41]. Data from Poland are to be collected.

This review aims to focus on the importance of the tear film in proper functioning of the OS and to highlight the role of its disorders as the manifestation of various diseases. 
Table I. The function of tear film layers

\begin{tabular}{|c|c|}
\hline Tear film layer & Function \\
\hline Lipids (meibum) & $\begin{array}{l}\text { - Form the outer layer of the tear film } \\
\text { - Minimize the evaporation of water from the eye surface } \\
\text { - Isolate ocular surface from the environment } \\
\text { - Improve the stability of tear film } \\
\text { - Provide smooth refracting surface } \\
\text { - Limit contamination of ocular surface from particles (dust) and microorganisms } \\
\text { - Prevent tear contamination by skin lipids } \\
\text { - Limit aqueous layer surface tension } \\
\text { - Counteract tears overflowing onto the skin }\end{array}$ \\
\hline Aqueous phase & $\begin{array}{l}\text { - Constitutes roughly } 90 \% \text { of the tear film volume } \\
\text { - Lubricates the ocular surface } \\
\text { - Washes away foreign bodies and contaminations } \\
\text { - Nourishes the avascular cornea (oxygen, proteins, inorganic salts) } \\
\text { - Includes proteins (lysozyme, lactoferrin, lipocalin), immunoglobulins, defensins and glycoproteins responsible for anti-microbial activity } \\
\text { - Includes growth factors, vitamins and electrolytes necessary for ocular surface health and epithelial integrity } \\
\text { - Realigns corneal microirregularities (refractive properties) }\end{array}$ \\
\hline Mucins & $\begin{array}{l}\text { - Form a glycocalyx over the ocular epithelium that prevents pathogen adhesion } \\
\text { - Bind water to hydrate and lubricate the ocular surface } \\
\text { - Reduce friction during blinking } \\
\text { - Clear the surface of pathogens and debris } \\
\text { - Contribute to tear stability } \\
\text { - Take part in regulation of epithelial growth } \\
\text { - Might be involved in cellular signaling }\end{array}$ \\
\hline
\end{tabular}

\section{CONDITIONS AFFECTING TEAR FILM LAYERS}

Each layer of the tear film can be affected by different diseases and conditions, thereby causing its instability. Because of the wide spectrum of the problems that may interfere with proper functioning of the tear film, diagnosis of particular disturbances may be challenging. The results of the most common tests may be quite similar in different disorders and further, more specific examinations are required.

\section{The lipid layer}

Damage to the outermost layer manifests itself primarily as a change of its thickness (lipid layer thickness - LLT). It can be measured by optical reflectometry using a slit lamp or single-wave interferometry, both of which are non-invasive techniques [42]. Interferometry of the tear film also allows for assessment of kinetic stability of the lipid phase [43]. From the available diagnostic tools only meibometry provides quantitative assessment of the lipid reservoir [44]. Increase in the tear film evaporation rate has been reported to be strongly correlated with lipid layer impairment, but its great dependence on extrinsic conditions decreases its diagnostic value [28]. Moreover, in normal conditions the tear surface tension is maintained by the lipids, so its rise may serve as a diagnostic clue. The higher proportion of branched fatty acid chains in Meibomian gland excreta also serves as a marker of lipid layer dysfunction [45]. Ring et al. introduced a promising novel parameter called corrected lipid layer stabilization time; however, further trials are needed before it can be recognized as a standard procedure [46].
Meibomian gland dysfunction (MGD) directly affects the composition and stability of the lipid layer, as those structures are almost exclusively responsible for lipid excretion to the tear film [47]. It can result from both hyper- and hyposecretion. Also, androgen deficiency, which occurs in patients on anti-androgen therapy and with aging, hinders lipid production [48]. Various local and systemic conditions may provoke obstructive defect to the glands, e.g. chronic blepharitis and atopy $[49,50]$. The more severe course of MGD is associated with type 2 diabetes mellitus $[51,52]$. Insufficient protein intake in bariatric patients also negatively influences tear film lipids [53]. Furthermore, it has been reported that incomplete blinking may be the reason for lipid layer instability, because of inadequate lipid distribution [5, 54]. Moreover, tobacco smokers are prone to development of MGD [55]. Demodicosis is another condition that should be named as a contributing factor. Demodex spp. can be found in eyelashes, with prevalence in healthy individuals ranging from $18 \%$ (age group of 21-35 years old) to $33 \%$ (> 65 years old) [56]. Otherwise harmless, mites are associated with marginal blepharitis and chalazion as a result of gland penetration [57]. Interestingly, a link between the number of mites and disease severity has been reported [58]. Recently, a small study presented a new in-office technique for infestation confirmation in patients with cylindrical dandruff [59].

There are some studies on medications, both topical and systemic, that may cause distortions specific to the lipid layer. Isotretinoin, used for acne treatment, decreases Meibomian gland secretory ability $[60,61]$. In contrast, botulinum neu- 
rotoxin A injections for blepharospasm and hemifacial spasm seem to increase LLT [62].

\section{The aqueous layer}

Examination of the middle, aqueous layer can be performed using various diagnostic tools. The tear meniscus assessment is of significant value [63], as it is a simple method for visualizing the tear film volume. A traditional, popular test for assessing tear secretion is the Schirmer I test, which can be performed with or without anesthesia. However, its results can be altered by the globe movements and eye position [64]. Another test that can describe the aqueous phase is the tear film osmolarity - its increase suggests a deficit of the aqueous compound [11, 65].

A dysfunction of the lacrimal glands leads to aqueous deficient dry eye. The diagnosis is established by the presence of subjective complaints and objective evidence of dry eye symptoms. Aqueous deficient dry eye can be classified into two groups: Sjögren syndrome dry eye and non-Sjögren syndrome dry eye [66].

Patients with Sjögren syndrome (SS) are a heterogeneous group of patients, among whom two common symptoms can be identified - keratoconjunctivitis and xerostomia [67]. Brito Zenon et al. showed in their cohort study that sicca manifestations occur in up to $98 \%$ of SS cases [68]. In addition to clinical presentation, biomarkers characteristic for SS include anti-Ro/SSA and anti-La/SSB autoantibodies [69]. The pathophysiology of Sjogren syndrome is of a dual origin. The primary SS occurs when symptoms from the lacrimal and saline glands are isolated, whereas the secondary SS is accompanied by connective tissue diseases such as rheumatoid arthritis (20-32\%), systemic lupus erythematosus (15-36\%), and progressive systemic sclerosis (11-24\%) [70]. In both types, the gland tissues are infiltrated by activated T-lymphocytes [71].

In the non-SS dry eye, we can distinguish lacrimal deficiency, lacrimal gland duct obstruction and reflex block [72]. In this type of eye dryness, the basal tear production is hindered. Many of the non-SS eye dryness cases are idiopathic, but some of the factors responsible for this disorder include: age-related atrophy and/or fibrosis of the lacrimal gland [73], Mikulicz disease (IgG4-positive plasmocytes infiltration) [74], other autoimmunological diseases (such as systemic lupus erythematosus, rheumatoid arthritis, autoimmune thyroiditis and chronic ocular graft versus host disease [75].

Moreover, keratoconjunctivitis sicca is linked to corneal hypoesthesia, occurring after corneal refraction surgery [76] and in patients wearing contact lenses [77]. Damage to the $\mathrm{V}$ cranial nerve may manifest as neurotrophic keratitis it is observed in some patients with Herpes zoster keratitis (12.8\%), in $6 \%$ of herpetic keratitis cases and as a side effect of surgical trigeminal neuralgia management (2.8\%) [78].

Aqueous layer stability can also be affected by medications - some antidepressants (escitalopram, venlafaxine, duloxetine) have been shown to reduce the values of the Schirmer I test [79] and depression has been linked to a higher probability of developing eye dryness [80]. Hydrochlorothiazide has also been reported to decrease tear production [81]. Retinoic acids, although often associated with aqueous deficiency, do not decrease water secretion $[82,83]$.

\section{The mucin layer}

The state of the mucin layer, which is directly adherent to the cornea, can be tested using various diagnostic techniques. Tear film osmolarity demonstrates the strongest correlation with disease severity, but results obtained using different measurement means may vary $[28,84]$. Also, tear wash levels of myeloperoxidase and metalloproteinases increase in mucous disorders [85]. Examination of the epithelial surface, i.e. conjunctival impression cytology, reveals lower goblet cell densities per millimeter compared to healthy subjects. Tear ferning is present in affected patients, which can be estimated with the ocular ferning test, but unfortunately unequivocal agreement on its interpretation is still lacking $[86,87]$. It is worth bearing in mind that very often patients suspected of problems with the mucin layer suffer from vitamin A deficiency, detectable in blood plasma.

The leading cause of xerophthalmia associated with mucins is related to insufficient vitamin A levels [88, 89]. This avitaminosis manifests itself in various ways and can be observed in the course of several illnesses and syndromes. Night blindness should be regarded as the most common symptom mentioned by the patients, apart from dry eye. In the direct eye examination Bitot's spots can be visible in the conjunctiva, along with xerosis and corneal scarring and even ulcers [90]. It is also characterized by the loss of goblet cells, whose growth strongly depends on vitamin A [91]. Generally, lack of vitamin $\mathrm{A}$ is associated with different forms of malnutrition or chronic malabsorption [92-94]. Some gastroenterological diseases such as celiac disease may serve as examples of the latter [92]. Moreover, any condition affecting the liver, hence challenging the fat metabolism, decreases the absorption rate of this fat-soluble vitamin $[95,96]$. The pancreas is closely involved in the fat digestion pathway and its insufficiency, such as in cystic fibrosis, hinders vitamin A intake $[97,98]$. Alcoholism is the major cause of malnutrition $[99,100]$, along with restrictive diets, both in eating disorders and a selective, e.g. poorly balanced, vegan diet, and consumption of low-quality food [101-103].

The second most common disease associated with mucin layer defects is mucous membrane pemphigoid (MMP) and its subtype ocular cicatricial pemphigoid (OCP), which affects the conjunctiva exclusively [104]. A recurrent inflammatory process destroys the mucous cells and promotes subepithelial fibrosis, resulting in conditions ranging from xerophthalmia to total conjunctival keratinization and blindness [105-108].

There are some other conditions affecting mucin production. Steven-Johnson syndrome, being a manifestation of adverse drug reactions, impairs the mucin layer of the tear film [109]. Its pathomechanism involves metaplasia of the conjunctiva and hence a decrease in the number of the goblet cells $[110,111]$. Severe burns, both chemical and thermal, can affect the conjunctival mucin production by decreasing the number of functioning goblet cells [112]. Of the pharmaco- 
logic factors, ambroxol, a popular oral mucoactive drug, has been found to modify the mucous layer [113].

\section{CONDITIONS AFFECTING MULTIPLE LAYERS}

Tear film layers remain in strict dependence on each other - in terms of both the functionality on the molecular level and the regulation of its secretion. Therefore, some conditions affect tear film as a whole, causing disturbances to each of its layers. The most common and definitely unavoidable condition impairing the ocular surface is progression in age, which hinders each step of tear production and secretion, although to a variable extent. Notably, it also influences other tear film impairing factors, mentioned below. Tantalic dry eyes, in all three subtypes, may seem to be the most obvious condition affecting all three layers - lid-eye incongruency, epitheliopathy and evaporation being the reasons for tear loss. Also, the neurologic cause should not be missed, as it directly affects tear secretion. Hormonal regulation, mainly by estrogens, androgens and prolactin, acts likewise [114-116].

As regards environmental factors, use of visual display terminals promotes dry eye disease, but the actual pathomechanism is still being discussed $[117,118]$. Contact lens wear, even though influencing mainly the lipid layer, changes the dynamics of the tear film as a whole, as reported in the Mann et al. report [119], and very often causes dry eye symptoms $[120,121]$.

Multiple layers of the tear film may also be affected by various medications, for instance, topical beta-blockers used by glaucomatous patients - studies report the decrease of Schirmer I test values and fluorescein break up time, and an increase in eye surface staining results [122, 123]. Moreover, there have been reports that topical glaucoma therapy significantly lowers LLT [124]. Additionally, the basal tear production decreases under long-term general anesthesia, causing perioperative dry eye syndrome [125]. The side effect of hindering both the goblet cells and lacrimal glands is associated with $\mathrm{H} 1$ antihistamines [126]. An extensive review and list of medications were presented by Askeroglu et al. [127]. Surprisingly, based on the latest metanalysis, the negative effect of hormonal replacement therapy and oral contraceptives on the tear film seems to be rather speculative $[128,129]$.

\section{CONCLUSIONS}

The problem of tear film disorders can overwhelm with its extensivity. Our review focused on selected aspects, which were chosen on the basis of clinical importance and prevalence. The broad spectrum of diseases and conditions that may affect each layer of the tear film impedes comprehensive depiction of them all. Defining the etiology and pathophysiology of some disturbances can be very complex, and represents clinical and therapeutic challenge. Notably, tear film disorders can manifest other systemic diseases and sometimes be the sole clue to diagnosis, so the subject should be considered as of great importance not only to ophthalmologists, but also to physicians of other specialties. Furthermore, the commonness of tear film instability and wide spectrum of its different backgrounds call for incorporating its general state evaluation into daily medical practice. If a patient has eye dryness symptoms, these complaints should also be taken into consideration when planning treatment. If a certain drug has been proven to cause tear film disturbance, a different substance should be considered. We believe that questions about eye problems should be a part of every medical history taken, and diagnostic tests, which assess the tear film function, should be a part of every ophthalmic examination.

\section{DISCLOSURE}

The authors declare no conflict of interest.

\section{References}

1. Cher I. Ocular surface concepts: development and citation. Ocul Surf 2014; 12: 10-13.

2. Sridhar MS. Anatomy of cornea and ocular surface. Indian J Ophthalmol 2018; 66: 190-194.

3. Holly FJ, Lemp MA. Tear physiology and dry eyes. Surv Ophthalmol 1977; 22: 69-87.

4. Craig JP, Nelson JD, Azar DT, et al. TFOS DEWS II Report Executive Summary. Ocul Surf 2017; 15: 802-812.

5. Yokoi N, Bron AJ, Georgiev GA. The precorneal tear film as a fluid shell: the effect of blinking and saccades on tear film distribution and dynamics. Ocul Surf 2014; 12: 252-266.

6. Jeyalatha MV, Qu Y, Liu Z, et al. Function of meibomian gland: contribution of proteins. Exp Eye Res 2017; 163: 29-36.

7. Arita R, Fukuoka S, Morishige N. Functional morphology of the lipid layer of the tear film. Cornea 2017; 36 Suppl 1: S60-S66.

8. Georgiev GA, Eftimov P, Yokoi N. Structure-function relationship of tear film lipid layer: a contemporary perspective. Exp Eye Res 2017; 163: 17-28.

9. Takahashi Y, Watanabe A, Matsuda $\mathrm{H}$, et al. Anatomy of secretory glands in the eyelid and conjunctiva: a photographic review. Ophthalmic Plast Reconstr Surg 2013; 29: 215-219.

10. Garg A, Zhang X. Lacrimal gland development: from signaling interactions to regenerative medicine. Dev Dyn 2017; 246: 970-980.

11. Willcox MDP, Argueso P, Georgiev GA, et al. TFOS DEWS II Tear Film Report. Ocul Surf 2017; 15:366-403.

12. Fong PY, Shih KC, Lam PY, et al. Role of tear film biomarkers in the diagnosis and management of dry eye disease. Taiwan J Ophthalmol 2019; 9: 150-159.

13. Paulsen FP, Berry MS. Mucins and TFF peptides of the tear film and lacrimal apparatus. Prog Histochem Cytochem 2006; 41: 1-53.

14. Gipson IK. Goblet cells of the conjunctiva: a review of recent findings. Prog Retin Eye Res 2016; 54: 49-63.

15. Gipson IK, Spurr-Michaud S, Tisdale A. Human conjunctival goblet cells express the membrane associated mucin MUC16: Localization to mucin granules. Exp Eye Res 2016; 145: 230-234.

16. Ablamowicz AF, Nichols JJ. Ocular surface membrane-associated mucins. Ocul Surf 2016; 14: 331-341.

17. Gipson IK. Distribution of mucins at the ocular surface. Exp Eye Res 2004; 78: 379-388.

18. Gipson IK, Argueso P. Role of mucins in the function of the corneal and conjunctival epithelia. Int Rev Cytol 2003; 231: 1-49. 
19. Hodges RR, Dartt DA. Tear film mucins: front line defenders of the ocular surface; comparison with airway and gastrointestinal tract mucins. Exp Eye Res 2013; 117: 62-78.

20. Tiffany JM. The normal tear film. Dev Ophthalmol 2008; 41: 1-20.

21. Research in dry eye: report of the Research Subcommittee of the International Dry Eye WorkShop (2007). 0cul Surf 2007; 5: 179-193.

22. Maurya RP, Bhushan P, Singh VP, et al. Immunoglobulin concentration in tears of contact lens wearers. J Ophthalmic Vis Res 2014; 9: $320-323$.

23. Sen DK, Sarin GS. Immunoglobulin concentrations in human tears in ocular diseases. Br J Ophthalmol 1979; 63: 297-300.

24. Allansmith M. Immunology of the tears. Int Ophthalmol Clin 1973; 13: 47-72.

25. Rolando M, Zierhut M. The ocular surface and tear film and their dysfunction in dry eye disease. Surv 0phthalmol 2001; 45 Suppl 2: S203-S210.

26. Braun RJ. Dynamics of the tear film. Annu Rev Fluid Mech 2012; 44: 267-297.

27. Stahl U, Willcox M, Stapleton F. Osmolality and tear film dynamics. Clin Exp Optom 2012; 95: 3-11.

28. Wolffsohn JS, Arita R, Chalmers R, et al. TFOS DEWS II Diagnostic Methodology Report. Ocul Surf 2017; 15: 539-574.

29. Szczesna DH, Alonso-Caneiro D, Iskander DR, et al. Predicting dry eye using noninvasive techniques of tear film surface assessment. Invest Ophthalmol Vis Sci 2011; 52: 751-756.

30. Gipson IK. The ocular surface: the challenge to enable and protect vision: the friedenwald lecture. Invest Ophthalmol Vis Sci 2007; 48: 4391-4398.

31. Song $P$, Xia W, Wang M, et al. Variations of dry eye disease prevalence by age, sex and geographic characteristics in China: a systematic review and meta-analysis. J Glob Health 2018; 8: 020503.

32. Wang $S$, Jia Y, Li T, et al. Dry eye disease is more prevalent in children with diabetes than in those without diabetes. Curr Eye Res 2019; 44: 1299-1305.

33. Rathnakumar K, Ramachandran K, Baba D, et al. Prevalence of dry eye disease and its association with dyslipidemia. J Basic Clin Physiol Pharmacol 2018; 29: 195-199.

34. Zhang S, Hong J. Risk factors for dry eye in mainland china: a multi-center cross-sectional hospital-based study. Ophthalmic Epidemiol 2019; 26: 393-399.

35. Yu D, Deng Q, Wang J, et al. Air pollutants are associated with dry eye disease in urban ophthalmic outpatients: a prevalence study in China. J Transl Med 2019; 17: 46.

36. Yu X, Guo H, Liu X, et al. Dry eye and sleep quality: a large community-based study in Hangzhou. Sleep 2019; 42: zsz160.

37. Chen L, Pi L, Fang J, et al. High incidence of dry eye in young children with allergic conjunctivitis in Southwest China. Acta Ophthalmol 2016; 94: e727-e730.

38. Stapleton F, Alves M, Bunya VY, et al. TFOS DEWS II Epidemiology Report. Ocul Surf 2017; 15: 334-365.

39. Gong YY, Zhang F, Zhou J, et al. Prevalence of dry eye in Uyghur and Han ethnic groups in western China. Ophthalmic Epidemiol 2017; 24: 181-187.

40. Viso E, Rodriguez-Ares MT, Gude F. Prevalence of and associated factors for dry eye in a Spanish adult population (The Salnes Eye Study). Ophthalmic Epidemiology 2009; 16: 15-21.

41. Farrand KF, Fridman M, Stillman I, Schaumberg DA. Prevalence of diagnosed dry eye disease in the United States among adults aged 18 years and older. Am J Ophthalmol 2017; 182: 90-98.

42. Lu H, Wang MR, Wang J, Shen M. Tear film measurement by optical reflectometry technique. J Biomed Opt 2014; 19:027001.

43. Goto E, Tseng SC. Differentiation of lipid tear deficiency dry eye by kinetic analysis of tear interference images. Arch Ophthalmol 2003; 121: 173-180.

44. Yokoi N, Komuro A. Non-invasive methods of assessing the tear film. Exp Eye Res 2004; 78: 399-407.

45. Joffre C, Souchier M, Gregoire S, et al. Differences in meibomian fatty acid composition in patients with meibomian gland dysfunction and aqueous-deficient dry eye. Br J Ophthalmol 2008; 92: 116-119.

46. Ring MH, Rabensteiner DF, Horwath-Winter J, et al. Introducing a new parameter for the assessment of the tear film lipid layer. Invest Ophthalmol Vis Sci 2012; 53: 6638-6644.

47. Chhadva P, Goldhardt R, Galor A. Meibomian gland disease: the role of gland dysfunction in dry eye disease. Ophthalmology 2017; 124: S20-S26.

48. Krenzer KL, Dana MR, Ullman MD, et al. Effect of androgen deficiency on the human meibomian gland and ocular surface. J Clin Endocrinol Metab 2000; 85: 4874-4882.

49. Shine WE, McCulley JP. Meibomian gland triglyceride fatty acid differences in chronic blepharitis patients. Cornea 1996; 15: 340-346.

50. Shine WE, McCulley JP. The role of cholesterol in chronic blepharitis. Invest Ophthalmol Vis Sci 1991; 32: 2272-2280.

51. Lin X, Xu B, Zheng Y, et al. Meibomian gland dysfunction in type 2 diabetic patients. J Ophthalmol 2017; $2017: 3047867$.

52. Garzón SJP, López-Alemany A, Gené-Sampedro A. Correlation between type 2 diabetes, dry eye and meibomian glands dysfunction. J Optom 2019; 12: 256-262.

53. Sanchez-Sanchez AS, Rodriguez-Murguia N, Martinez-Cordero C, Chavez-Cerda S. Protein diet in bariatric patients could modify tear film. Obes Surg 2020; 30: 2053-2055.

54. Wang MTM, Tien L, Han A, et al. Impact of blinking on ocular surface and tear film parameters. Ocul Surf 2018; 16: 424-429.

55. Zakrzewska A, Machalińska A. Risk factors for meibomian gland dysfunction. Klin Oczna 2018; 120: 236-241.

56. Biernat MM, Rusiecka-Ziolkowska J, Piatkowska E, et al. Occurrence of Demodex species in patients with blepharitis and in healthy individuals: a 10-year observational study. Jpn J Ophthalmol 2018; 62: 628-633.

57. Moris Garcia V, Valenzuela Vargas G, Marin Cornuy M, Aguila Torres P. Ocular demodicosis: A review. Arch Soc Esp Oftalmol 2019; 94: 316-322.

58. Lee SH, Chun YS, Kim JH, et al. The relationship between demodex and ocular discomfort. Invest Ophthalmol Vis Sci 2010; 51: 29062911.

59. Man Peles I, Zahavi A, Chemodanova E, Vardizer Y. Novel in-office technique for visual confirmation of demodex infestation in blepharitic patients. Cornea 2020; 39: 858-861.

60. Brzezinski P, Borowska K, Chiriac A, Smigielski J. Adverse effects of isotretinoin: a large, retrospective review. Dermatol Ther 2017; 30.

61. Moy A, McNamara NA, Lin MC. Effects of isotretinoin on meibomian glands. Optom Vis Sci 2015; 92: 925-930. 
62. Ho RW, Fang PC, Chao TL, et al. Increase lipid tear thickness after botulinum neurotoxin A injection in patients with blepharospasm and hemifacial spasm. Sci Rep 2018; 8: 8367.

63. Wei A, Le Q, Hong J, et al. Assessment of lower tear meniscus. Optom Vis Sci 2016; 93: 1420-1425.

64. Bitton E, Wittich W. Influence of eye position on the Schirmer tear test. Cont Lens Anterior Eye 2014; 37: 257-261.

65. Potvin R, Makari S, Rapuano CJ. Tear film osmolarity and dry eye disease: a review of the literature. Clin Ophthalmol 2015; 9: 20392047.

66. Lin H, Yiu SC. Dry eye disease: A review of diagnostic approaches and treatments. Saudi J Ophthalmol 2014; 28: 173-181.

67. de Paiva CS, Rocha EM. Sjögren syndrome: what and where are we looking for? Curr Opin Ophthalmol 2015; 26: 517-525.

68. Brito-Zeron P, Theander E, Baldini C, et al. Early diagnosis of primary Sjögren's syndrome: EULAR-SS task force clinical recommendations. Expert Rev Clin Immunol 2016; 12: 137-156.

69. Jonsson R, Brokstad KA, Jonsson MV, et al. Current concepts on Sjögren's syndrome - classification criteria and biomarkers. Eur J Oral Sci 2018; 126 Suppl 1: 37-48.

70. Tomiak C, Dorner T. Sjögren's syndrome. Current aspects from a rheumatological point of view. Z Rheumatol 2006; 65: 505-517; quiz 518-519.

71. Voulgarelis M, Tzioufas AG. Current aspects of pathogenesis in Sjögren's syndrome. Ther Adv Musculoskelet Dis 2010; 2: 325-334.

72. Craig JP, Nichols KK, Akpek EK, et al. TFOS DEWS II Definition and Classification Report. Ocul Surf 2017; 15: 276-283.

73. Obata H, Yamamoto S, Horiuchi H, Machinami R. Histopathologic study of human lacrimal gland. Statistical analysis with special reference to aging. Ophthalmology 1995; 102: 678-686.

74. Wallace ZS, Zhang Y, Perugino CA, et al. Clinical phenotypes of IgG4-related disease: an analysis of two international cross-sectional cohorts. Ann Rheum Dis 2019; 78: 406-412.

75. Munir SZ, Aylward J. A review of ocular graft-versus-host disease. Optom Vis Sci 2017; 94: 545-555.

76. Bragheeth MA, Dua HS. Corneal sensation after myopic and hyperopic LASIK: clinical and confocal microscopic study. Br J Ophthalmol 2005; 89: 580-585.

77. Murphy PJ, Patel S, Marshall J. The effect of long-term, daily contact lens wear on corneal sensitivity. Cornea 2001; 20: 264-269.

78. Feroze KB, Patel BC. Neurotrophic keratitis. StatPearls. Treasure Island (FL) 2020.

79. Koçer E, Koçer A, Özsütçü M, et al. Dry eye related to commonly used new antidepressants. J Clin Psychopharmacol 2015; 35: 411-413.

80. Tiskaoglu NS, Yazıı A, Karlıdere T, et al. Dry eye disease in patients with newly diagnosed depressive disorder. Curr Eye Res 2017; 42: $672-676$.

81. Bergmann MT, Newman BL, Johnson NC, Jr. The effect of a diuretic (hydrochlorothiazide) on tear production in humans. Am J Ophthalmol 1985; 99: 473-475.

82. Aslan Bayhan S, Bayhan HA, Çölgeçen E, Gürdal C. Effects of topical acne treatment on the ocular surface in patients with acne vulgaris. Cont Lens Anterior Eye 2016; 39: 431-434.

83. Caglar C, Senel E, Sabancilar E, Durmus M. Reduced ocular surface disease index (OSDI) scores in patients with isotretinoin treatment. Int Ophthalmol 2017; 37: 197-202.

84. Miserocchi E, luliano L, Berchicci L, et al. Tear film osmolarity in ocular mucous membrane pemphigoid. Cornea 2014; 33: 668-672.

85. Arafat SN, Suelves AM, Spurr-Michaud S, et al. Neutrophil collagenase, gelatinase, and myeloperoxidase in tears of patients with Stevens-Johnson syndrome and ocular cicatricial pemphigoid. Ophthalmology 2014; 121: 79-87.

86. Tabbara KF, Okumoto M. Ocular ferning test. A qualitative test for mucus deficiency. Ophthalmology 1982; 89: 712-714.

87. Masmali AM, Purslow C, Murphy PJ. The tear ferning test: a simple clinical technique to evaluate the ocular tear film. Clin Exp Optom 2014; 97: 399-406.

88. Wiseman EM, Bar-El Dadon S, Reifen R. The vicious cycle of vitamin a deficiency: a review. Crit Rev Food Sci Nutr 2017; 57: 37033714.

89. Whatham A, Bartlett $H$, Eperjesi $F$, et al. Vitamin and mineral deficiencies in the developed world and their effect on the eye and vision. Ophthalmic Physiol Opt 2008; 28: 1-12.

90. Gilbert C. The eye signs of vitamin A deficiency. Community Eye Health 2013; 26: 66-67.

91. Sommer A, Green WR. Goblet cell response to vitamin A treatment for corneal xerophthalmia. Am J Ophthalmol 1982; 94: 213-215.

92. Chiu M, Dillon A, Watson S. Vitamin A deficiency and xerophthalmia in children of a developed country. J Paediatr Child Health 2016; 52: 699-703.

93. da Cruz SP, Matos A, Pereira S, et al. Roux-en-Y gastric bypass aggravates vitamin A deficiency in the mother-child group. Obes Surg 2018; 28: 114-121.

94. Cheshire J, Kolli S. Vitamin A deficiency due to chronic malabsorption: an ophthalmic manifestation of a systemic condition. BMJ Case Rep 2017; 2017: bcr2017220024.

95. Kemp CM, Jacobson SG, Faulkner DJ, Walt RW. Visual function and rhodopsin levels in humans with vitamin A deficiency. Exp Eye Res 1988; 46: 185-197.

96. Prasad D, Bhriguvanshi A. Ocular manifestations of liver disease in children: Clinical aspects and implications. Ann Hepatol 2019; S1665-2681(19)32293-8.

97. Morkeberg JC, Edmund C, Prause JU, et al. Ocular findings in cystic fibrosis patients receiving vitamin A supplementation. Graefes Arch Clin Exp Ophthalmol 1995; 233: 709-713.

98. Norsa L, Zazzeron L, Cuomo M, et al. Night blindness in cystic fibrosis: the key role of vitamin A in the digestive system. Nutrients 2019; 11: 1876.

99. Roncone DP. Xerophthalmia secondary to alcohol-induced malnutrition. Optometry 2006; 77: 124-133.

100. Kopecky A, Benda F, Nemcansky J. Xerosis in patient with vitamin A deficiency - a case report. Cesk Slov Oftalmol 2018; 73: 222-224.

101. Martini S, Rizzello A, Corsini I, et al. Vitamin A deficiency due to selective eating as a cause of blindness in a high-income setting. Pediatrics 2018; 141 (Suppl 5): S439-S444.

102. Jaworowski S, Drabkin E, Rozenman Y. Xerophthalmia and undiagnosed eating disorder. Psychosomatics 2002; 43: 506-507.

103. Kirby M, Danner E. Nutritional deficiencies in children on restricted diets. Pediatr Clin North Am 2009; 56: 1085-1103.

104. Chan LS, Ahmed AR, Anhalt GJ, et al. The first international consensus on mucous membrane pemphigoid: definition, diagnostic criteria, pathogenic factors, medical treatment, and prognostic indicators. Arch Dermatol 2002; 138: 370-379. 
105. Chan LS. Ocular and oral mucous membrane pemphigoid (cicatricial pemphigoid). Clin Dermatol 2012; 30: 34-37.

106. Saw VP, Dart JK. Ocular mucous membrane pemphigoid: diagnosis and management strategies. Ocul Surf 2008; 6: 128-142.

107. Ahmed M, Zein G, Khawaja F, Foster CS. Ocular cicatricial pemphigoid: pathogenesis, diagnosis and treatment. Prog Retin Eye Res 2004; 23: 579-592.

108. Queisi MM, Zein M, Lamba N, et al. Update on ocular cicatricial pemphigoid and emerging treatments. Surv Ophthalmol 2016; 61:314-317.

109. Arstikaitis MJ. Ocular aftermath of Stevens-Johnson syndrome. Arch Ophthalmol 1973; 90: 376-379.

110. Ralph RA. Conjunctival goblet cell density in normal subjects and in dry eye syndromes. Invest Ophthalmol 1975; 14: 299-302.

111. Wright $P$, Collin JR. The ocular complications of erythema multiforme (Stevens Johnson syndrome) and their management. Trans Ophthalmol Soc U K 1983; 103 (Pt 3): 338-341.

112. Lin A, Patel N, Yoo D, et al. Management of ocular conditions in the burn unit: thermal and chemical burns and Stevens-Johnson syndrome/toxic epidermal necrolysis. J Burn Care Res 2011; 32: 547-560.

113. Kim D, Kim HJ, Hyon JY, et al. Effects of oral mucolytics on tear film and ocular surface. Cornea 2013; 32: 933-938.

114. Murube J, Benitez del Castillo JM, Chenzhuo L, et al. The Madrid triple classification of dry eye. Arch Soc Esp Oftalmol 2003; 78 : 587-593; 595-601.

115. Murube J, Nemeth J, Hoh H, et al. The triple classification of dry eye for practical clinical use. Eur J Ophthalmol 2005; 15: 660-667.

116. Truong S, Cole N, Stapleton F, Golebiowski B. Sex hormones and the dry eye. Clin Exp 0ptom 2014; 97:324-336.

117. Courtin R, Pereira B, Naughton $G$, et al. Prevalence of dry eye disease in visual display terminal workers: a systematic review and meta-analysis. BMJ Open 2016; 6: e009675.

118. Hanyuda A, Sawada N, Uchino M, et al. Physical inactivity, prolonged sedentary behaviors, and use of visual display terminals as potential risk factors for dry eye disease: JPHC-NEXT study. Ocul Surf 2020; 18: 56-63.

119. Mann A, Tighe B. Contact lens interactions with the tear film. Exp Eye Res 2013; 117: 88-98.

120. Lim CHL, Stapleton F, Mehta JS. Review of contact lens-related complications. Eye Contact Lens 2018; 44 Suppl 2: S1-S10.

121. Alipour F, Khaheshi S, Soleimanzadeh M, et al. Contact lens-related complications: a Review. J Ophthalmic Vis Res 2017; 12: 193-204.

122. Ohtsuki M, Yokoi N, Mori K, et al. Adverse effects of beta-blocker eye drops on the ocular surface. Nippon Ganka Gakkai Zasshi 2001; 105: 149-154.

123. Nielsen NV, Eriksen JS. Timolol transitory manifestations of dry eyes in long term treatment. Acta Ophthalmol (Copenh) 1979; 57: 418-424.

124. Lee SM, Lee JE, Kim SI, et al. Effect of topical glaucoma medication on tear lipid layer thickness in patients with unilateral glaucoma. Indian J Ophthalmol 2019; 67: 1297-1302.

125. Zernii EY, Golovastova M0, Baksheeva VE, et al. Alterations in tear biochemistry associated with postanesthetic chronic dry eye syndrome. Biochemistry (Mosc) 2016; 81: 1549-1557.

126. Bielory L. Ocular toxicity of systemic asthma and allergy treatments. Curr Allergy Asthma Rep 2006; 6: 299-305.

127. Askeroglu U, Alleyne B, Guyuron B. Pharmaceutical and herbal products that may contribute to dry eyes. Plast Reconstr Surg 2013; 131: 159-167.

128. Dang A, Nayeni M, Mather R, et al. Hormone replacement therapy for dry eye disease patients: systematic review and meta-analysis. Can J Ophthalmol 2020; 55: 3-11.

129. Moschos MM, Nitoda E. The impact of combined oral contraceptives on ocular tissues: a review of ocular effects. Int J Ophthalmol 2017; 10: 1604-1610. 